\title{
The Relationship between Environmental Temperature, Metabolic Rate, Sleep State, and Evaporative Water Loss in Infants from Birth to Three Months
}

\author{
Y. AZAZ, P. J. FLEMING, M. LEVINE, R. MCCABE, A. STEWART, AND P. JOHNSON \\ Institute of Child Health [Y.A., P.J.F., R.M., A.S.] and Department of Physiology [M.L.], University of Bristol, \\ Bristol, United Kingdom, and Nuffield Department of Obstetrics and Gynaecology, John Radcliffe Hospital, \\ Oxford, United Kingdom [P.J.]
}

\begin{abstract}
We have investigated the effect of changing environmental temperature on metabolic rate, sleep state, and water loss in a longitudinal study of 22 lightly clothed babies from $2 \mathrm{~d}$ to $3 \mathrm{mo}$ of age. Studies were performed in a modified barometric plethysmograph while recording sleep state, oxygen consumption, and skin and axillary temperatures. Oxygen consumption was higher in rapid eye movement sleep than in quiet sleep at all ages and varied widely between infants at each temperature. Within the first week, there was a $19 \%$ rise in oxygen consumption on cooling to $19-22^{\circ} \mathrm{C}$ during rapid eye movement sleep and a $6 \%$ rise during quiet sleep. The median duration of quiet sleep periods was reduced from 17 to $12 \mathrm{~min}$ on cooling within the first week. No such change was seen at 1,2 , and 3 mo. Axillary temperature was reduced at 3 mo during cooling. This may be a part of normal patterns of change in temperature during sleep, unrelated to cooling. At each age, total evaporative water loss fell linearly with falling environmental temperature both within and below the temperature range at which metabolic rate was minimal. The evaporative water losses were greater than expected and suggested that sweating was occurring, both at temperatures at which metabolic rate was minimal and at those at which it was increased. The metabolic response to cooling and the process of sweating appear to be in dynamic equilibrium across this temperature range. Thus, it was not possible to define a temperature range over which both metabolic rate and evaporative water loss were at minimum values. (Pediatr Res 32: 417-423, 1992)
\end{abstract}

\section{Abbreviations}

$\mathrm{VO}_{2}$, oxygen consumption

QS, quiet sleep

REM, rapid eye movement sleep

The relationship between environmental temperature and $\mathrm{VO}_{2}$ has been previously studied in term infants $(1-3)$. The lower end of the thermoneutral range has been defined and is lower at 3 wk of age than at $1 \mathrm{~d}$, in both naked and cot-nursed babies, and might be assumed to fall further with increasing age (4). The

Received January 10, 1992; accepted May 11, 1992.

Correspondence and reprint requests: Dr. P. J. Fleming, Department of Child Health, St. Michael's Hospital, Southwell St., Bristol, BS2 8EG Great Britain.

Supported by research grants from The Foundation for the Study of Infant Deaths (Project No. 45), Action Research (Project No. S/P/1705), and Cot Death Research. effect of sleep state on metabolic rate has been studied both in adults (5) and in babies within the first week at thermoneutral and cooler temperatures (6-8). In all these studies, metabolic rate was higher in REM. However, little information is available on the relationship between sleep state and environmental temperature, or on thermoneutrality, at older ages in infancy.

We have investigated the effect of mild cold stress on metabolism and water loss (both respiratory and transcutaneous) during both REM and QS in infants from the first week to 3 mo of age.

\section{MATERIALS AND METHODS}

Twenty-two normal, healthy infants, free from known adverse risk factors were selected. All the infants were born at term (gestational age from 37.5 to $42 \mathrm{wk}$ ) to healthy mothers and had a median birth weight of $3.44 \mathrm{~kg}$ (range $3.1-4.74 \mathrm{~kg}$ ). None experienced significant perinatal problems or had any major illnesses during the first $3 \mathrm{mo}$. Each infant was studied once during the first week (median age $49 \mathrm{~h}$, range 16-143 h) and on one to three further occasions, at 1,2 , and $3 \mathrm{mo}$. Polygraphic recordings of sleep state and respiration were performed using a barometric plethysmograph (9), which allows accurate recordings of respiration in unrestrained babies. The barometric plethysmograph was modified to allow recordings of metabolic rate.

Plethysmograph/metabolic chamber. The baby's head was covered by a Perspex (ICI Products, Welling Garden City, Hertfordshire, England) head box (volume $2 \mathrm{~L}$ ) with a light polythene neck cover. There was a hole in the side of the head box to allow controlled air flow in through a series of baffles. The maximum velocity of airflow over the infants head was less than $6 \mathrm{~cm} / \mathrm{s}$ for all flow rates used in these studies. The head box was connected via a sealed Perspex mixing chamber containing a precision hair hygrometer and thermometer to the air outlet of the plethysmograph. The flow of gas from the plethysmograph was recorded using a certified calibrated KDG Instruments (Crawley, West Sussex, UK) 1100 series rotameter. Part of the flow $(100 \mathrm{~mL} /$ $\mathrm{min}$ ) from the rotameter was dried and passed through a Servomex (Crowborough, Sussex, UK) 1100 paramagnetic oxygen analyzer. The pressure inside the optical cell of the oxygen analyzer was kept constant. The temperature of the cell was servo controlled, and the instrument was surrounded by a high thermal capacity enclosure. Another part of the outflow of gas $(100 \mathrm{~mL} /$ min) from the plethysmograph was dried and passed through a Beckman LB2 infrared carbon dioxide analyzer (Cardiokinetics Ltd., Salford, UK). The signals were recorded onto FM tape (Racal store 4, Racal Ltd., Southampton, UK) and chart recorders (Devices M19, Ormed Ltd. and J. J. Lloyd CR600, Warsash, Southampton, UK). 
The inflow and outflow of air to and from the plethysmograph were maintained at equal values throughout each study such that the baby's chamber pressure remained within $5 \mathrm{~cm} \mathrm{H}_{2} \mathrm{O}$ of atmospheric pressure. Dry Medical Air (20.95\% oxygen, $0.03 \%$ carbon dioxide, balance nitrogen) was flowed into the plethysmograph throughout each study at a rate of 2 to $3 \mathrm{~L} / \mathrm{min} / \mathrm{kg}$ body weight.

A system of copper pipes and baffles was built into the plethysmograph around the walls, and an inner wall of 2-mm thick Perspex with multiple perforations was constructed to prevent accidental contact of the baby with the pipes. These perforations allowed free circulation of air between the pipes and the air inside the chamber. The Perspex wall, being opaque to infrared radiation, ensured that the effective wall temperature to which the baby was exposed was that measured on this surface. A solution of $40 \%$ ethylene glycol was circulated through the pipes to raise or lower the environmental temperature within the plethysmograph. This fluid was drawn through the pipes by suction as a safety feature to avoid any possible blowout. Two small fans were positioned adjacent to the walls to ensure complete mixture of air between the inner two walls of the chamber and within the chamber.

Validation of method of recording $\mathrm{VO}_{2}$. The gas measurements were validated by simulating $\mathrm{VO}_{2}$ under operating conditions. A fine catheter was attached to the nostril of a resuscitation doll that was lying inside the plethysmograph in the position in which an infant would lie. Using a certified calibrated rotameter (KDG Instruments 1100 as previously described), known flows of $100 \%$ nitrogen gas were passed through the catheter, giving predictable concentrations of oxygen in the plethysmograph outflow and thus simulating $\mathrm{VO}_{2}$ over a range of $5 \mathrm{~mL} / \mathrm{min}$ to $40 \mathrm{~mL} / \mathrm{min}$.

Plots of observed values against expected values for $\mathrm{VO}_{2}$ showed close linear relationships $(r=0.99)$ and small, nonsystematic errors (standard error of observed values versus expected values was less than $5 \%$ of the expected values). Integration of the cumulative errors over $1 \mathrm{~min}$ gave values for such errors that were $<11 \%$ at all values of $\mathrm{VO}_{2}$. This procedure was performed for a range of gas outflows between 6 and $12 \mathrm{~L} / \mathrm{min}$, with similar results at all rates of gas outflow. It was not possible to validate the recording of oxygen concentration using the alcohol burning technique because the recording chamber was completely sealed and could not be operated during the burning of the alcohol.

Study protocol. The infants were prone, with one side slightly elevated and the head turned to that side, inside the plethysmograph and were wearing standardized light clothing, with no hat and covered with two layers of a standardized blanket (total thermal resistance of bedding and clothing $=\sim 2.5 \mathrm{tog}$ ) (10). The plethysmograph was closed when the infants fell asleep. The studies were performed for the duration of a sleep period between two feeds commencing at least 45 min after the beginning of the feed (11). Recordings were initially made during both QS and REM at temperatures expected to be within the thermoneutral range. The chamber was then cooled to within $3-5^{\circ} \mathrm{C}$ below that range (reaching $17-21^{\circ} \mathrm{C}$ within 20 to $30 \mathrm{~min}$ ), and the study continued until the infants woke up (median duration of cooling period $29 \mathrm{~min}$, range 4-90 min). For infants older than $1 \mathrm{mo}$, the recordings were started at temperatures within the expected thermoneutral range for a baby aged $3 \mathrm{wk}$.

Environmental temperatures were displayed and recorded from Yellow Springs Instruments probes (Yellow Springs, $\mathrm{OH}$ ) at the following sites: the plethysmograph internal surfaces [wall and lid $(\mathrm{Tl})$ ], the air inside the plethysmograph (Ta), and the headbox air (Th). The infant's skin (on the lower anterior shin) and axillary temperatures were also recorded (the axillary and both the air probes were model 401 , time constant $7 \mathrm{~s}$; all surface probes were model 409B, time constant $1.1 \mathrm{~s}$ ). The axillary probe was always positioned on the side that was slightly downward during the study, and this arm was firmly positioned close to the baby's side with the blanket around it. The use of the axilla was thought to be more acceptable to parents than rectal probes and to improve follow-up attendance.

To validate axillary temperature as a measure of core temperature, both rectal $(5 \mathrm{~cm}$ within the rectum) and axillary temperatures were recorded in eight studies on seven babies at ages from 9 to 80 d. From 139 sets of observations at environmental temperatures between 31 and $19^{\circ} \mathrm{C}$, the mean recto-axillary difference was $0.4^{\circ} \mathrm{C}$, SD $0.29^{\circ} \mathrm{C}(95 \%$ confidence limits $0.35-$ $0.45)$. The recto-axillary temperature difference showed no significant change with the age of the baby. Hence, it was considered appropriate to use the axilla for core temperature measurement.

The effective environmental temperature was considered to be $(\mathrm{Ta}+\mathrm{Tl}+\mathrm{Th}) / 3$. This formula gives more weight to the headbox air temperature than the formula of Gagge (12). Although the head only makes up $21 \%$ of the total body surface area (13), its metabolic rate is such that exposure of the head results in a disproportionate cooling effect. From the data of Stothers (14), it was estimated that in the conditions of these studies the head would account for at least $33 \%$ of the total heat loss. Ta and $\mathrm{Tl}$ were usually within $0.5^{\circ} \mathrm{C}$ of each other and so were treated equally.

Room temperature and barometric pressure were recorded at the beginning and end of each study. The air outflow rate, temperature, and relative humidity were recorded at 3- to 5-min intervals throughout each study. As part of the study protocol, the cooling process was stopped if the infant's axillary temperature fell below $35.5^{\circ} \mathrm{C}$.

Throughout all the studies, the concentration of carbon dioxide in the headbox was maintained at less than $0.5 \%$ to avoid significant rebreathing of carbon dioxide. All infants were weighed naked at the end of each recording.

Sleep state. Sleep state was determined from parallel recordings of EEG and electrooculogram together with observation (15). After each study, sections of QS and REM were identified and marked on the oxygen concentration chart record. Only sections that met all the criteria for sleep state determination were included in the metabolic calculations.

Calculation of $\mathrm{VO}_{2}$. To ensure that a steady state had been reached, sections within $5 \mathrm{~min}$ of a change in sleep state or the beginning of cooling were not included in the calculations. Sections of recording during which gross body movement occurred were not excluded, but 5 -min periods were chosen in which individual periods of movement lasted less than $15 \mathrm{~s}$ (Episodes of movement lasting longer than $15 \mathrm{~s}$ occurred predominantly in REM). A total of three to 12 sections of recording were identified for analysis within each study. The Servomex analyzer was calibrated at the start and end of each study (to determine drift) using certified gases of known concentration. Measurements of oxygen concentration were made from the chart at 30-s intervals for one or more periods of $5 \mathrm{~min}$ in each state at each temperature. $\mathrm{VO}_{2}$ was calculated for each of the selected 5-min sections of recording and corrected to values at $\operatorname{stp}($ dry). The values obtained were then expressed as $\mathrm{mL} / \mathrm{min} /$ $\mathrm{kg}$ body weight.

Determination of evaporative water loss. The air entering the plethysmograph chamber was dry; thus, the water vapor in the air leaving the chamber represented the total evaporative water loss, including the respiratory losses. The diaper was covered with an impermeable plastic layer so that urinary and fecal losses were retained within the diaper. Recordings were only commenced when a steady state was reached for the outflow air relative humidity, usually within 10 to $15 \mathrm{~min}$ of closing the chamber, by which time relative humidity had risen to about $50 \%$.

From the Smithsonian Tables, the weight in grams of saturated water vapor in a cubic meter of air at each outflow temperature (w) was obtained (16). Then, for any value of relative humidity $(\mathrm{RH})$, total water loss $(\mathrm{mg} / \mathrm{kg} / \mathrm{min})=[\mathrm{w} \times \mathrm{RH} \times$ air outflow rate $(\mathrm{L} / \mathrm{min})] /$ body weight $(\mathrm{kg})$.

Respiratory water loss was determined as follows: The baro- 
metric plethysmograph records respiration by detecting the change in pressure caused by the warming and humidification of inspired air. From this signal, tidal volume and minute ventilation (Ve) were derived using a Fortran program developed in our laboratory. Previous work at these study temperatures has shown that expired gas leaves the nose fully saturated with water vapor at a temperature of $31^{\circ} \mathrm{C}(9)$. Thus, respiratory water loss $(\mathrm{mg} / \mathrm{kg} / \mathrm{min})=\mathrm{Ve}(\mathrm{mL} / \mathrm{min}) \times$ weight $(\mathrm{g})$ of $1 \mathrm{~mL}$ saturated water vapor at $31^{\circ} \mathrm{C}$, and nonrespiratory water loss $=$ total water loss - respiratory water loss.

Statistical analysis was by $t$ test and the Mann-Whitney $U$ test.

The study was approved by the hospital ethical committee, and informed consent was obtained from both parents, most of whom were present with their babies for at least one of the studies.

\section{RESULTS}

A total of 19 successful recordings were made in the first week, 11 at $1 \mathrm{mo}, 12$ at $2 \mathrm{mo}$, and 12 at $3 \mathrm{mo}$.

$\mathrm{VO}_{2}$ and thermoneutrality. The mean values for $\mathrm{VO}_{2}$ at different temperatures in REM and QS within the first week are shown in Figure $1 a$ and $b$, respectively. A rise in $\mathrm{VO}_{2}$ was seen at temperatures below $22-23^{\circ} \mathrm{C}$. Figure $2 a-c$ shows the mean values for $\mathrm{VO}_{2}$ in $\mathrm{REM}$ and $\mathrm{QS}$ over the same temperature range at 1 , 2 , and $3 \mathrm{mo}$, respectively. At $1 \mathrm{mo}$ (Fig. $2 a$ ), there was a rise in $\mathrm{VO}_{2}$ as the temperature fell below $23^{\circ} \mathrm{C}$, but at 2 and 3 mo the pattern was less clear because of the very wide variation between individual infants. Values for the temperature below which $\mathrm{VO}_{2}$ rose (i.e. the lower critical temperature) for individual babies

a.
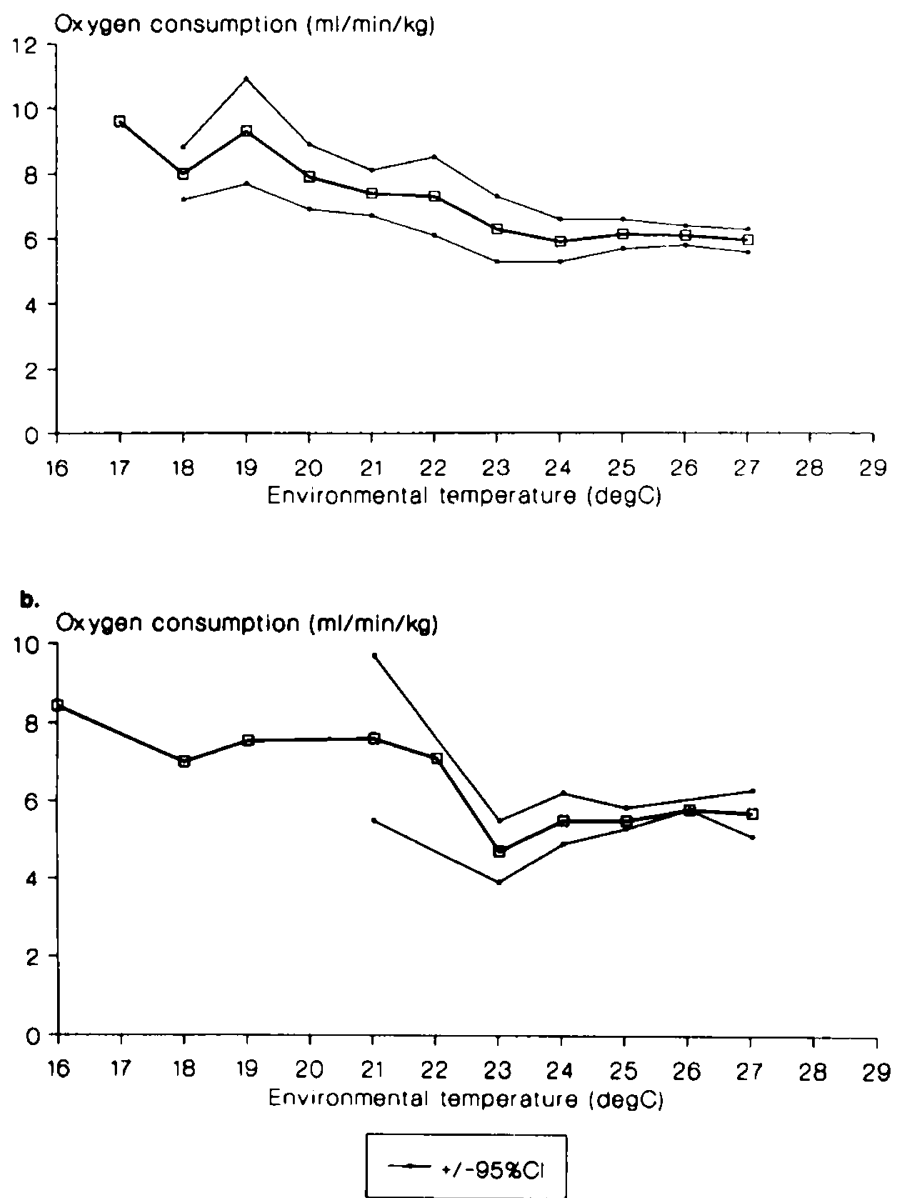

Fig. 1. Variation in mean $\mathrm{VO}_{2}$ with environmental temperature for infants less than 1 wk old during $\operatorname{REM}(a)$ and $\mathrm{QS}(b) . \mathrm{VO}_{2}$ in $\mathrm{mL} / \mathrm{kg} /$ $\min$, with $95 \%$ confidence intervals.
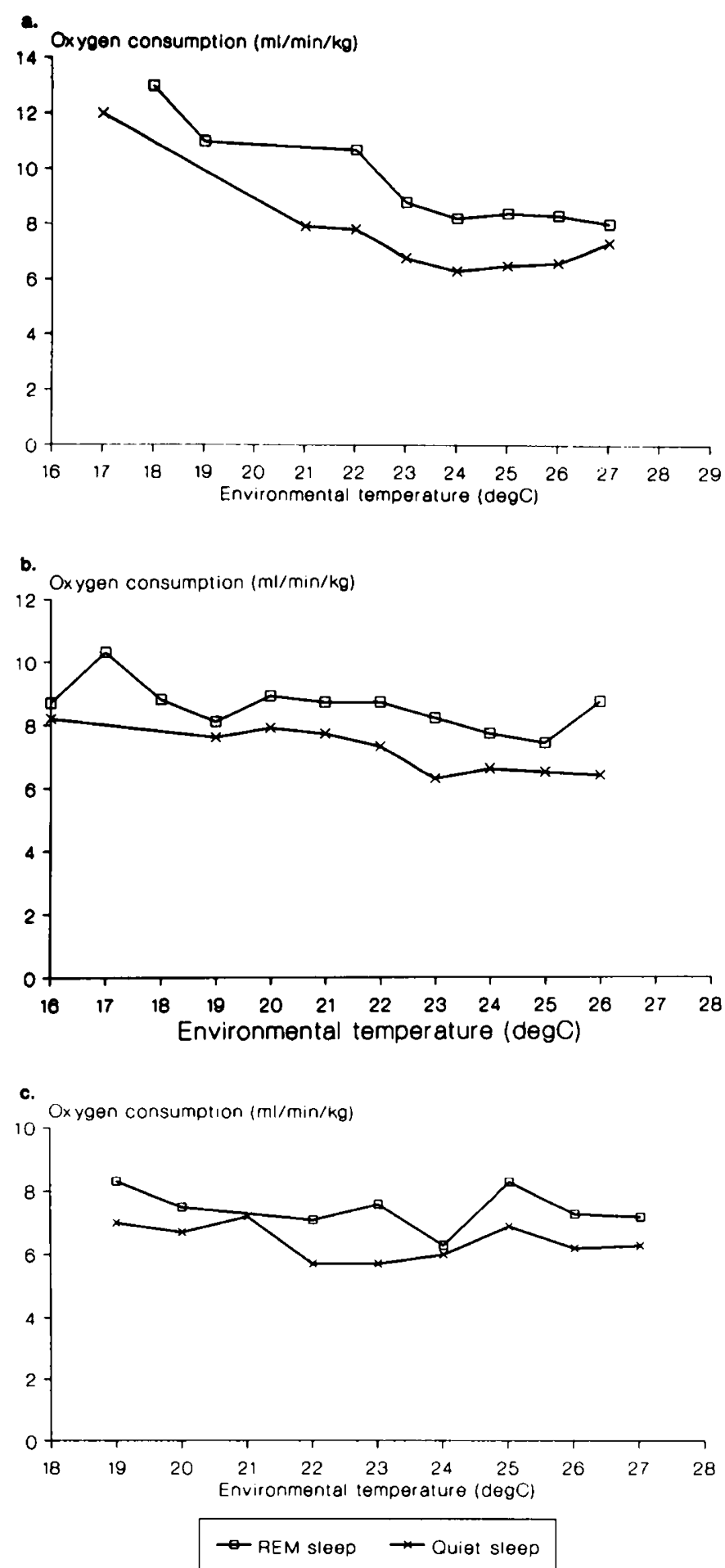

Fig. 2. The variation in mean $\mathrm{VO}_{2}$ with environmental temperature during QS and REM for infants aged $1 \mathrm{mo}(a), 2 \mathrm{mo}(b)$, and $3 \mathrm{mo}(c)$. $\mathrm{VO}_{2}$ in $\mathrm{mL} / \mathrm{kg} / \mathrm{min}$.

varied between 19 and $24^{\circ} \mathrm{C}$ for infants at 3 mo of age. The interpretation of these changes was complicated by the sleep state changes (see below).

At each age the lowest values for $\mathrm{VO}_{2}$ were achieved within the temperature range $23-27^{\circ} \mathrm{C}$. Thus, this environmental temperature range was considered to be within the thermoneutral range.

$\mathrm{VO}_{2}$ and sleep state. Table 1 and Figure $3 a$ and $b$ show the mean values for $\mathrm{VO}_{2}$ in the environmental temperature range $23-27^{\circ} \mathrm{C}$ in QS and REM at each age expressed both per unit 
Table 1. Mean $\mathrm{VO}_{2}$ in $Q S$ and $R E M$ at each age for all recordings performed within temperature range of $23-27^{\circ} \mathrm{C}^{*}$

\begin{tabular}{|c|c|c|c|c|c|c|c|c|}
\hline & \multicolumn{2}{|c|}{ Less than $1 \mathrm{wk}$} & \multicolumn{2}{|c|}{$1 \mathrm{mo}$} & \multicolumn{2}{|c|}{$2 \mathrm{mo}$} & \multicolumn{2}{|c|}{$3 \mathrm{mo}$} \\
\hline & REM & QS & REM & QS & REM & QS & REM & QS \\
\hline $\begin{array}{l}\mathrm{VO}_{2}(\mathrm{~mL} / \mathrm{min} / \mathrm{kg}) \\
\mathrm{SD}\end{array}$ & $\begin{array}{l}5.92 \\
0.69\end{array}$ & $\begin{array}{l}5.4 \dagger \\
0.50\end{array}$ & $\begin{array}{l}7.97 \ddagger \\
0.81\end{array}$ & $\begin{array}{l}6.45+\ddagger \\
0.88\end{array}$ & $\begin{array}{l}7.55 \ddagger \\
1.38\end{array}$ & $\begin{array}{l}6.49+\ddagger \\
1.35\end{array}$ & $\begin{array}{l}7.89 \S \\
2.07\end{array}$ & $\begin{array}{l}6.69+\S \\
1.94\end{array}$ \\
\hline $\begin{array}{l}\mathrm{VO}_{2}\left(\mathrm{~mL} / \mathrm{min} / \mathrm{m}^{2}\right) \\
\mathrm{SD}\end{array}$ & $\begin{array}{c}91.6 \\
9.89\end{array}$ & $\begin{array}{r}84.8 \dagger \\
6.58 \\
\end{array}$ & $\begin{array}{r}133.5 \ddagger \\
13.14 \\
\end{array}$ & $\begin{array}{c}108.0 \dagger \ddagger \\
14.65 \\
\end{array}$ & $\begin{array}{r}137.2 \ddagger \\
24.83 \\
\end{array}$ & $\begin{array}{c}118.8 † \ddagger \\
24.06\end{array}$ & $\begin{array}{r}145.6 \ddagger \\
37.94 \\
\end{array}$ & $\begin{array}{c}124.9+\ddagger \\
35.85 \\
\end{array}$ \\
\hline
\end{tabular}

* Values for $\mathrm{VO}_{2}$ given at stp. Significance of differences determined by paired $t$ test.

$\dagger p<0.05$, comparing QS with REM at each age.

$\ddagger p<0.05$ comparing 1 wk with 1,2 , and 3 mo, respectively, in each sleep state.

$\S$ NS comparing 1 wk with 3 mo.
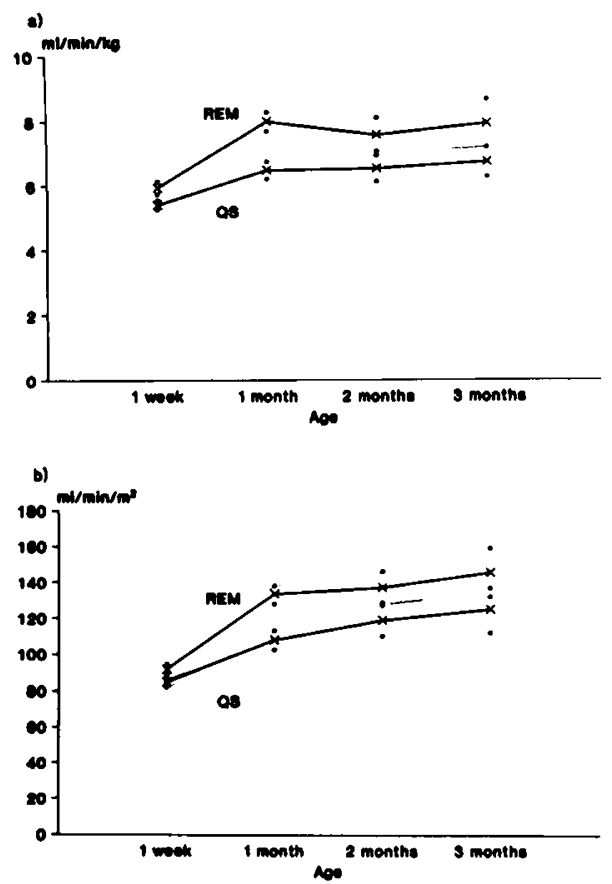

Fig. 3. The variation in mean $\mathrm{VO}_{2}$ with age in $\mathrm{QS}$ and $\mathrm{REM}$ for recordings performed within the temperature range $23-27^{\circ} \mathrm{C}$ expressed in $\mathrm{mL} / \mathrm{min} / \mathrm{kg}(a)$ and expressed in $\mathrm{mL} / \mathrm{min} / \mathrm{m}_{2}(b)$. Shown $\pm 95 \%$ confidence intervals.

weight and per unit surface area. $\mathrm{VO}_{2}$ was higher in REM than in QS. In both REM and QS, there was a significant rise in $\mathrm{VO}_{2}$ between the first week and $1 \mathrm{mo}$. When expressed in terms of weight, there was a $33.3 \%$ increase in $\mathrm{VO}_{2}$ in REM between the first week and $3 \mathrm{mo}$. When expressed in terms of surface area, this amounted to a $59 \%$ increase. Most of this increase occurred between 1 wk and 1 mo.

Cooling and sleep state. The metabolic response to cooling varied widely between babies and depended upon the sleep state at the time of cooling. Therefore, the differences in the metabolic response to cooling in REM and QS could only be assessed from the results of those studies in which the infant remained in the same state for a minimum of $5 \mathrm{~min}$ before and after cooling. Within the first week, the mean rise in $\mathrm{VO}_{2}$ on cooling from an environmental temperature of $23-27^{\circ} \mathrm{C}$ to one of $19-21^{\circ} \mathrm{C}$ in REM was $19 \%$ (range 5 to $41 \%$ ) and in QS was $5.9 \%$ (range -14 to $43 \%$ ). At the older ages, fewer infants remained in the same sleep state before and after the cooling process. At $3 \mathrm{mo}$ of age, two infants remained in REM during cooling to similar temperatures as given above, and their rises in $\mathrm{VO}_{2}$ during that period were 35 and $18.4 \%$. Four infants remained in QS during a period of cooling, and the changes in $\mathrm{VO}_{2}$ were $-7.1,-4.2,-3.6$, and $14.9 \%$.

Table 2 shows the median duration of REM and QS periods at thermoneutral $\left(23-27^{\circ} \mathrm{C}\right)$ and lower $\left(17-22^{\circ} \mathrm{C}\right)$ temperatures.
Table 2. Median duration (min) and range of individual $R E M$ and QS periods at temperatures between 23 and $27^{\circ} \mathrm{C}(T N)$ and 19 and $22^{\circ} \mathrm{C}(\mathrm{COOL})$ at age groups studied ${ }^{*}$

\begin{tabular}{lcccc}
\hline & Less than & & & \\
& $1 \mathrm{wk}$ & $1 \mathrm{mo}$ & $2 \mathrm{mo}$ & $3 \mathrm{mo}$ \\
\hline TN REM & 17.0 & 22.0 & 18.0 & 12.0 \\
Range & $8-28$ & $10-32$ & $7-25$ & $9-38$ \\
COOL REM & $28.5 \dagger$ & $20.5 \ddagger$ & $21.5 \ddagger$ & $13.0 \ddagger$ \\
Range & $13-98$ & $10-61$ & $17-30$ & $7-18$ \\
TN QS & 18.0 & 25.0 & 20.5 & 23.0 \\
Range & $10-26$ & $17-33$ & $10-45$ & $12-32$ \\
COOL QS & $12.5 \dagger$ & $14.0 \ddagger$ & $21.0 \ddagger$ & $20.0 \ddagger$ \\
Range & $9-17$ & $8-20$ & $21-27$ & $16-38$ \\
\hline
\end{tabular}

* The duration of sleep state periods is compared in each temperature band (Mann-Whitney $\mathrm{U}$ test).

$+p<0.05$.

$\ddagger$ NS.

Within the first week, there was a significant increase in the time spent in REM and a reduction in the time spent in QS on cooling. No significant changes in the duration of individual QS or REM periods were seen in the studies in older infants.

During cooling, there were increases in small and gross body movements in both sleep states at all ages. This was most marked in the older infants, often leading to the infant waking up within minutes of starting the cooling process, commonly before the effective environmental temperature had fallen below $23^{\circ} \mathrm{C}$.

Infant axillary and peripheral skin temperatures. Table 3 shows median values for axillary and peripheral skin temperatures during QS and REM at environmental temperatures of $23-27^{\circ} \mathrm{C}$ for all ages studied. There was no significant difference in axillary or peripheral skin temperature between sleep states at all ages. There was an increase in peripheral skin temperature between 1 wk and 3 mo $(p<0.001$, Mann-Whitney $U$ test $)$. There was a decrease in axillary temperature between 1 wk and 3 mo $(p<$ 0.001 , Mann Whitney U test).

Infant temperature responses to cooling. Figure 4 shows the respective mean falls in peripheral skin and axillary temperatures during environmental cooling below $23^{\circ} \mathrm{C}$ in infants within the first week and at $3 \mathrm{mo}$. At $3 \mathrm{mo}$, there was a greater fall in axillary and peripheral skin temperature during cooling than within the first week $(p<0.01$; Mann Whitney U test). In three out of nine studies on infants aged 3 mo in which the environmental temperature was lowered by $>4^{\circ} \mathrm{C}$, axillary temperature fell below $35.5^{\circ} \mathrm{C}$ and cooling was therefore stopped.

Evaporative water loss. The mean values obtained in all babies for total evaporative water loss during QS and REM at ambient temperatures between 23 and $27^{\circ} \mathrm{C}$ is compared at each age in Table 4. There was no significant difference between the two sleep states at any age and little change with age. Table 5 shows mean respiratory and nonrespiratory water losses for those babies in whom steady state values for minute ventilation and water loss were obtained at both warm $\left(23-27^{\circ} \mathrm{C}\right)$ and cool $\left(19-22^{\circ} \mathrm{C}\right)$ environmental conditions within the first week $(n=5)$ and at 3 
TEMPERATURE, METABOLISM, AND SLEEP IN INFANTS

Table 3. Median values for axillary (Tax) and peripheral skin (Tsk) temperatures during QS and REM sleep within environmental temperature range of $23-27^{\circ} \mathrm{C}$

\begin{tabular}{|c|c|c|c|c|c|c|c|c|}
\hline & \multicolumn{2}{|c|}{ Less than $1 \mathrm{wk}$} & \multicolumn{2}{|c|}{$1 \mathrm{mo}$} & \multicolumn{2}{|c|}{$2 \mathrm{mo}$} & \multicolumn{2}{|c|}{$3 \mathrm{mo}$} \\
\hline & REM & QS & REM & QS & REM & QS & REM & QS \\
\hline Tax & 36.4 & 36.4 & 36.4 & 36.3 & 35.8 & 35.7 & 36.1 & 36.1 \\
\hline & 0.41 & 0.45 & 0.39 & 0.43 & 0.66 & 0.56 & 0.39 & 0.38 \\
\hline Paired $t$ test ${ }^{*}$ & \multicolumn{2}{|c|}{ NS } & \multicolumn{2}{|c|}{ NS } & \multicolumn{2}{|c|}{ NS } & \multicolumn{2}{|c|}{ NS } \\
\hline Tsk & 33.6 & 33.7 & 34.0 & 33.5 & 33.7 & 33.6 & 34.3 & 34.5 \\
\hline & 0.76 & 0.85 & 2.21 & 1.76 & 1.56 & 1.51 & 1.07 & 0.86 \\
\hline Paired $t$ test $^{*}$ & \multicolumn{2}{|c|}{ NS } & \multicolumn{2}{|c|}{ NS } & \multicolumn{2}{|c|}{ NS } & \multicolumn{2}{|c|}{ NS } \\
\hline
\end{tabular}

* Comparing REM with QS.

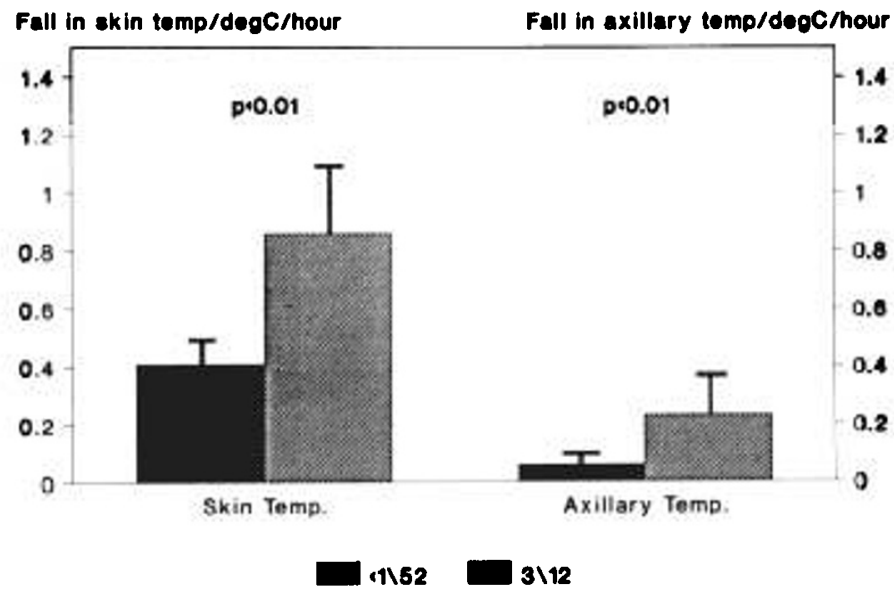

Fig. 4. The mean fall in peripheral skin and axillary temperatures with environmental cooling in infants less than 1 wk old and 3 mo old. Expressed in ${ }^{\circ} \mathrm{C}$ fall in body temperature per ${ }^{\circ} \mathrm{C}$ fall in environmental temperature per hour. Black bar, infants less than $1 \mathrm{wk}$ old; cross-hatched har, infants 3 mo old. $p<0.01$ (Mann-Whitney $U$ test). T bar denotes SEM.

mo $(n=6)$. At the higher temperatures, mean respiratory water loss was $7.12 \mathrm{mg} / \mathrm{kg} / \mathrm{min}(31.5 \%$ of the total) and $7.43 \mathrm{mg} / \mathrm{kg} /$ min $(24.4 \%$ of the total) within the first week and at $3 \mathrm{mo}$, respectively. However, this was increased to 56.7 and $44.4 \%$ of the total within the first week and at $3 \mathrm{mo}$, respectively, at the lower ambient temperatures. Respiratory water loss was increased (in parallel with increased minute ventilation) and nonrespiratory water loss was reduced during cooling.

Figure 5 shows the changes in mean nonrespiratory evaporative water loss with environmental temperature within the first week and at $3 \mathrm{mo}$. There was a reduction in nonrespiratory water loss with falling environmental temperature both across and below the range of temperatures at which $\mathrm{VO}_{2}$ was minimal at both ages. As with $\mathrm{VO}_{2}$, there was a wide individual variation in nonrespiratory evaporative water loss.

\section{DISCUSSION}

Thermoneutrality. These studies show considerable variation in the lower critical temperature for metabolic rate at each age, especially in the older infants, but no consistent change over the ages studied. Thus, it was not possible to define the lower end of the thermoneutral range for the older infants. At all ages studied, $\mathrm{VO}_{2}$ was at minimum levels within the range $23-27^{\circ} \mathrm{C}$. In several of the infants studied at 3 mo of age, there was no change in $\mathrm{VO}_{2}$ on cooling despite a fall in axillary temperature (see below).

Metabolic rate and sleep state. $\mathrm{VO}_{2}$ was consistently higher during REM than in QS at all the ages studied. This confirms and extends the observations of Stothers and Warner (6) on babies within the first week.

The mean $\mathrm{VO}_{2}$ at 1,2 , and 3 mo was higher than within the first week in both QS and REM. The rise in $\mathrm{VO}_{2}$ in the first month may be related to the increased demand of growth and coincides with the known rise in heart and respiratory rates at this age (17). The use of unit surface area is preferable when comparing $\mathrm{VO}_{2}$ at the different ages because of the changes in weight:surface area ratio. These data show that infants at 3 mo excreted substantially more heat per unit surface area than at 1 wk despite the thicker subcutaneous fat layer at 3 mo.

Infant temperature. The pattern of axillary and peripheral skin temperatures at environmental temperatures between 23 and $27^{\circ} \mathrm{C}$ varied between $1 \mathrm{wk}$ and $3 \mathrm{mo}$. At $3 \mathrm{mo}$, there was a reduction in axillary temperature despite increased heat production. This was reflected in a higher peripheral skin temperature through which the extra heat could be lost from the body. Several studies have shown a reduction in core temperature in 3- to 4 . month-old infants during sleep as part of the development of circadian sleep cycles $(18,19)$.

Cooling, sleep state, and body temperature. During the first week, the metabolic response to mild cooling was greater during REM than in QS. It was difficult to make this comparison in many cases at the older ages because the infants commonly changed sleep state or woke up relatively soon after cooling commenced. However, in the six infants in whom data are available at 3 mo of age, the metabolic response to cooling was also greater during REM than in QS.

At lower environmental temperatures, during the first week, the infants spent less time in QS and more time in REM. Thus, a significant part of the response to cold stress was a behavioral one, with a preferential switching into the state (REM) in which the metabolic response was more effective. At 1, 2, and $3 \mathrm{mo}$, there was no significant change in the proportion of either QS or REM time during cooling though many of these infants woke shortly after the onset of cooling and many showed an increase in small body movements, particularly in REM. This is in contrast to the findings of Hey and O'Connell (20), who described

Table 4. Mean values for total insensible water loss $(\mathrm{mg} / \mathrm{kg} / \mathrm{min})$ during $Q S$ and $R E M$ sleep at each age within temperature range of $23-27^{\circ} \mathrm{C}$

\begin{tabular}{|c|c|c|c|c|c|c|c|c|}
\hline & \multicolumn{2}{|c|}{ Less than 1 wk } & \multicolumn{2}{|c|}{$1 \mathrm{mo}$} & \multicolumn{2}{|c|}{$2 \mathrm{mo}$} & \multicolumn{2}{|c|}{$3 \mathrm{mo}$} \\
\hline & REM & QS & REM & QS & REM & QS & REM & QS \\
\hline Mean & 28.43 & 29.0 & 27.22 & 28.36 & 23.39 & 23.98 & 33.5 & 34.0 \\
\hline SD & 6.00 & 6.00 & 4.07 & 4.36 & 0.53 & 1.77 & 8.45 & 10.12 \\
\hline Paired $t$ test ${ }^{*}$ & \multicolumn{2}{|c|}{ NS } & \multicolumn{2}{|c|}{ NS } & \multicolumn{2}{|c|}{ NS } & \multicolumn{2}{|c|}{ NS } \\
\hline
\end{tabular}

* Comparing REM with QS. 
Table 5. Mean respiratory and nonrespiratory (Nonresp) water losses $(\mathrm{mg} / \mathrm{kg} / \mathrm{min}$ ) at environmental temperatures between 23 and $27^{\circ} \mathrm{C}$ and 19 and $22^{\circ} \mathrm{C}$ for infants within first week and at 3 mo old

\begin{tabular}{lccccc}
\hline & \multicolumn{2}{c}{$23-27^{\circ} \mathrm{C}$} & & \multicolumn{2}{c}{$19-22^{\circ} \mathrm{C}$} \\
\cline { 2 - 3 } \cline { 5 - 6 } \cline { 5 - 6 } & Respiratory & Nonresp & & Respiratory & Nonresp \\
\hline L1 wk & 7.12 & 15.6 & & 9.62 & 7.36 \\
SD & 1.79 & 4.39 & & 2.47 & 2.57 \\
3 mo & 7.43 & 22.96 & & 8.27 & 11.36 \\
SD & 2.42 & 8.99 & & 2.45 & 5.48 \\
\hline
\end{tabular}
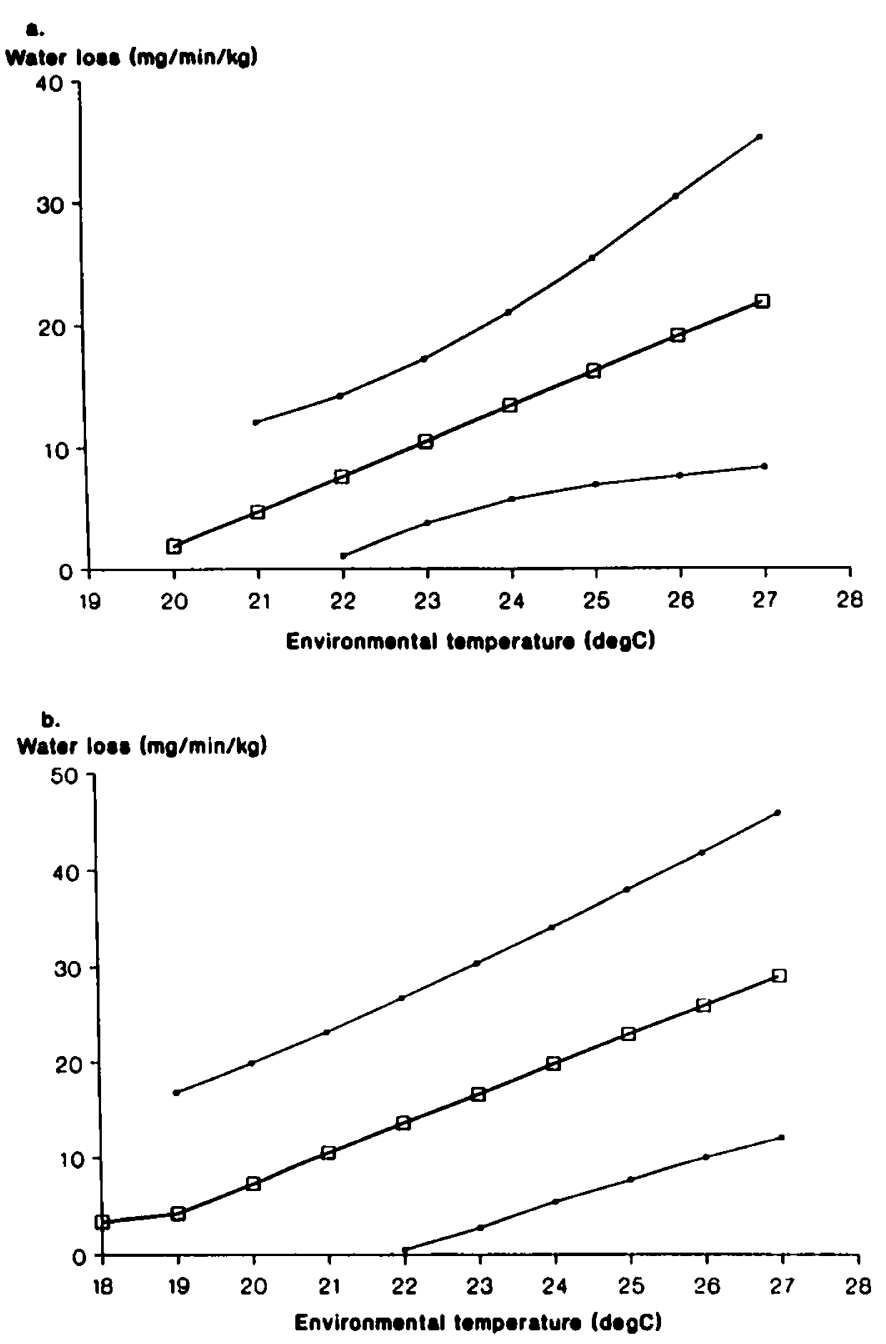

Fig. 5. The variation in mean nonrespiratory evaporative water loss with environmental temperature for infants studied within the first week $(a)$ and at 3 mo of age $(b)( \pm 95 \%$ confidence intervals). Environmental temperature in ${ }^{\circ} \mathrm{C}$.

how none of their clothed study infants cried or moved in response to cooling. Waking or movement in response to falling environmental temperature may be an important behavioral response. However, the increase in body movements may have resulted in the infants waking because they moved their arms against the inside of the headbox or plethysmograph.

When infants were cooled, within the first week they showed an increase in $\mathrm{VO}_{2}$ but little reduction in peripheral skin or axillary temperature. Mestyan et al. (21) suggested that the rise in $\mathrm{VO}_{2}$ during cooling was secondary to a fall in skin temperature, and Bruck (1) demonstrated changes in skin blood flow during cooling within the first days of life. A reduction in skin blood flow leading to a fall in skin temperature would be the predictable response in an attempt to minimize heat loss by increasing thermal resistance. The smaller changes in skin temperature on cooling within the first week may reflect the low tissue insulation at this age, resulting in radiant heat loss directly from the deep body, and an immaturity of the vasomotor control system in some babies (22). An increase in $\mathrm{VO}_{2}$ without increasing skin vasoconstriction might result in a loss of body heat and an eventual fall in core body temperature. This did not occur in any of the babies studied within the first week, showing the effectiveness of nonshivering thermogenesis at this age.

The fall in axillary temperature in some infants at 3 mo during cooling may reflect a fall in core temperature or be a manifestation of extreme peripheral vasoconstriction such that the axillary temperature was no longer a true reflection of core temperature. The close correlation that we observed between axillary and rectal temperatures in the infants in which both were measured makes this latter explanation less likely, but none of the infants in whom we recorded both rectal and axillary temperature showed a major fall in axillary temperature during cooling.

An alternative explanation would be that the observed reduction in axillary temperature during cooling was further evidence of the previously described changes in core body temperature after 30-60 min of sleep in infants in the home. The cooling in many of our studies occurred 30-60 min after sleep onset; thus, the fall in axillary temperature in the 3-mo-old infants may not have been entirely due to the effects of environmental cooling. It is of interest that these changes were seen less frequently in the younger infants, for whom the relationship between mass and surface area and the thinner subcutaneous fat layer might have been expected to lead to an increased vulnerability to cold stress. Even in the infants less than $1 \mathrm{wk}$ old, in whom a relatively lower metabolic rate might make them more vulnerable to cooling, little fall in axillary temperature was observed during cooling. Thus, the fall in axillary temperature in the 3-mo-old infants may reflect a maturation of the relationship between metabolism and sleep/wake cycles whereby body temperature falls during sleep.

It is also possible, however, that for 3-mo-old infants the thermal set point is less vigorously maintained under conditions of mild cold stress than in younger infants. The emergence of a circadian rhythm of body temperature may be important at this age in producing differences between daytime and nighttime studies.

Cooling and evaporative water loss. In this study, there was no significant difference in water loss between QS and REM at thermoneutral temperatures. This contrasts with the finding of Stothers and Warner (8), who found an increase in both water loss and skin heat loss in REM. This may be accounted for by the different techniques used in the two studies for determination of water loss. Respiratory water loss was increased at lower environmental temperatures. This reflects the increase in minute ventilation accompanying the rise in $\mathrm{VO}_{2}$ during cooling.

Our studies show a consistent fall in nonrespiratory water loss with a lowering of environmental temperature within and below the thermoneutral range. Other studies demonstrated a basal plateau effect for evaporative water loss at and below temperatures at which $\mathrm{VO}_{2}$ was minimal, but this was not present in our studies (23). We have previously reported that expired gas is saturated at $31^{\circ} \mathrm{C}$, whereas previous studies had assumed a temperature of $37^{\circ} \mathrm{C}$. This assumption leads to a $31 \%$ overestimate of respiratory water losses (9). Because respiratory losses increase with metabolic rate and minute ventilation as environmental temperature falls, this overestimate of respiratory losses is most marked at lower temperatures and will lead to a marked underestimation of nonrespiratory water losses. This difference in calculated respiratory water losses may account for some of the difference between our figures and those previously published. Thus, in our study, nonrespiratory evaporative water loss continued to fall as the environmental temperature fell $3-5^{\circ} \mathrm{C}$ below the range at which metabolic rate was minimal. This evaporative 
water loss was greater than would be expected from passive transepidermal evaporation $(24,25)$. Previous studies of water loss in infants have used humidified air in the study chamber, whereas the air entering the plethysmograph was dry. Even though our studies were only commenced at steady state for the chamber relative humidity, it is possible that the constant entry of dry air may have increased skin water losses.

Another explanation might be that some infants were sweating at a temperature at which the metabolic response to cooling (a rise in $\mathrm{VO}_{2}$ ) occurred. This apparent overlap, with active processes of heat production and heat loss occurring at the same temperature, may be an artifact of the speed of temperature change within our chamber, but this seems unlikely because cooling was relatively slow, taking $20-30 \mathrm{~min}$ to achieve a steady state fall of $5-6^{\circ} \mathrm{C}$. Thus, the metabolic response to cooling and the process of evaporative water loss could be in a state of dynamic equilibrium across this temperature range. Such a dynamic equilibrium would be in keeping with the known behavior of other homeostatic control systems.

The "optimal" environmental temperature might be considered to be that temperature at which both metabolic rate and nonrespiratory water losses were close to minimum values, as both control systems would be expending minimum energy. Although no single temperature that met those conditions could be defined at any of the ages studied, the range of temperatures just above and just below the lower critical temperature came closest to meeting them. Thus, from the point of view of energy expenditure, the lower critical temperature may be considered optimal. The wide range observed for the lower critical temperature in different infants makes this a very difficult temperature to define.

\section{REFERENCES}

1. Bruck K 1961 Temperature regulation in the newborn infant. Biol Neonate 3:65-119

2. Hill JR, Rahimtulla KA 1965 Heat balance and the metabolic rate of newborn babies in relation to environmental temperature, and the effect of age and of weight on basal metabolic rate. J Physiol (Lond) 180:239-265

3. Hey EN 1969 The relation between environmental temperature and oxygen consumption in the newborn baby. J Physiol (Lond) 200:589-603
4. Hey EN 1971 In: Gairdner D, Hull D (eds) The care of babies in incubators. In: Recent Advances in Paediatrics. Churchill, London, pp 171-213

5. Palca JW, Walker JM, Berger RJ 1986 Thermoregulation, metabolism and stages of sleep in cold-exposed men. J Appl Physiol 61:940-947

6. Stothers JK Warner RM 1978 Oxygen consumption and neonatal sleep state J Physiol (Lond) 278:435-440

7. Fleming PJ, Levine MR, Azaz Y, Johnson P 1988 The effect of sleep state on the metabolic response to cold stress in newborn infants. In: Jones CT (ed) Fetal and Neonatal Development. Perinatology Press, New York, pp 635639

8. Stothers JK, Warner RM 1984 Thermal balance and sleep state in the newborn. Early Hum Dev 9:313-322

9. Fleming PJ, Levine MR, Goncalves A, Woollard S 1983 Barometric plethysmograph: advantages and limitations in recording infant respiration. J Appl Physiol 55:1924-1931

10. Clulow E 1978 Thermal insulating properties of fabrics. Textiles $1: 2$

11. Stothers JK, Warner RM 1979 The effect of feeding on neonatal oxygen consumption. Arch Dis Child 54:415-420

12. Gagge AP 1940 Standard operative temperature, a generalized temperature scale, applicable to direct and partial calorimetry. Am J Physiol 131:93-103

13. Boyd E 1935 The Growth of the Surface Area of the Human Baby. University of Minnesota Press, Minneapolis, pp 100-102

14. Stothers JK 1981 Head insulation and heat loss in the newborn. Arch Dis Child 56:530-534

15. Anders T, Emde R, Parmelee A 1971 A Manual of Standardized Terminology, Techniques and Criteria for Scoring States of Sleep and Wakefulness in Newborn Infants. BRI Publications Office, Los Angeles

16. Weast RC (ed) 1987-1988 CRC Handbook of Chemistry and Physics, 68th Ed. CRC Press, Boca Raton. FL, pp E-4!

17. Carse EA, Wilkinson AR, Whyte P, Henderson-Smart DJ, Johnson P 198 Oxygen and carbon dioxide tensions, breathing and heart rate in normal infants during the first six months of life. J Dev Physiol 3:85-100

18. Lodemore M, Peterson SA, Wailoo MP 1991 Development of night time temperature rhythms over the first six months of life. Arch Dis Child 66:521524

19. Wailoo MP, Peterson SA, Whittaker H, Goodenough P (1989) Sleeping body temperatures in 3-4 month old infants. Arch Dis Child 64:596-599

20. Hey EN, O'Connell B 1970 Oxygen consumption and heat balance in the cotnursed baby. Arch Dis Child 45:335-343

21. Mestyan J, Jarai I, Bata G, Fekete M 1964 Surface temperature versus deep body temperature and the metabolic response to cold of hypothermic premature infants. Biol Neonate 7:230-242

22. Burton AC 1934 The application of the theory of heat flow to the study of energy metabolism. J Nutr 7(suppl):497-533

23. Hey EN, Katz G 1969 Evaporative water loss in the newborn baby. J Physiol (Lond) 200:605-619

24. Rutcer N, Hull D 1979 Water loss from the skin of term and preterm babies. Arch Dis Child 54:858-868

25. Sedin G, Hammarlund K, Nilsson GE, Stomberg B, Oberg PA 1985 Measurement of transepidermal water loss in newborn infants. Clin Perinatol 12:7999 